\title{
Eğitimde Psikolojik Açıdan Normale Duyulan İhtiyaç, Normalin Ölçüsü ve Çeşitleri
}

\author{
Dr. Osman SEZGIN \\ Marmara Üniversitesi, Eğitim Fakültesi, Göztepe Kampüsü \\ Kadıköy / İstanbul / Türkiye
}

Kavram kargaşası giderilmeden, să̆lıklı ve doğru düşünülemez dolayısıyla

anlamlı tartışmalar ve çözümler üretilemez.

-Platon-

\section{Özet}

Batılılaşma gayreti içinde olan devletler, her alanda ve bilhassa bilimde, Batı'nın bir iz düşümü gibi, onların takipçileri olmuşlardır. Bilhassa sosyal bilimlerde, insan ve eğitim bilimleri alanlarındaki tercümelerle, bu devletler Batıyı adım adım takip etmekte ve yapılan yayınlarda, Batı'daki indekslerde taranan dergiler daha makbul ve onların hakemliği daha itibar edilir durumda olmaktadır. Bu hâlin olumlu yönleri olduğu kadar, olumsuz yönleri de bulunmaktadır. Bilhassa çevirilerde ve bilimsel ifâdelerin anlaşılmasında, bu durum, büyük yanlışlıklara, sıkıntılara sebebiyet vermektedir. Bu sıkıntılı durumların başında, psikolojik alandaki kelime ve kavramların İngilizcedeki karşılıkları veya tercümedeki hatalar gelmektedir. Bilhassa, 
son zamanlarda çokça tartış1lan, normal ve normalin ölçüsü ile normal çerçevesi içinde üstün zekâll, üstün yetenekli ve çoklu zekâ kavramları gelmektedir. Özel eğitim denildiğinde veya normal veya anormal denildiğinde, ciddi bir kavram kargaşası olduğu gözlenmektedir. "Yetenek nedir, zekâ nedir, normal nedir, normalin ölçüsü nedir, kaç tür normal dışılık vardır?" gibi soruların tam anlatılamamasının veya anlaşılamamasının asıl sebeplerinden birinin, bu kavramların anlam ve sınırlılıklarının tam bilinmemesi olduğu, gözlemlerle ve yazılan makalelerin okunması ile kolayca anlaşılabilmektedir. Bu kargaşayı, özellikle normal çerçevesinde, bir nebze de olsa açıklığa kavuşturmak için gereğinin; normalin tanımı, ölçüsü ve çeşitlilikleri ile ilgili böyle bir makalenin yazılmasının ana sebebini oluşturduğu söylenmelidir.

Anahtar Kelimeler: Normal; Anormal; Paranormal; Zekâ; Yetenek; Özel eğitim; Kelime ve kavram kargaşası.

\title{
Necessity of Normal in Terms of Psychology in Educations as Well as The Criteria and Kinds of Normal
}

\begin{abstract}
The states spending efforts to be Westernized for the last two, even three hundred years in almost all fields, especially in science, have just become the followers of them as if it has been a perspective drawing of the West. They have been step by step following the West through translations done in especially social siences as well as in the field of human sciences and education and in the meantime the sientific journals scanned by the Western indexes have been found more acceptable and their arbitration have been more prestigious. Although this situation produces positive aspects, it creates also negative results. Especially in translations and in explanation of scientific statements, it causes huge mistakes. The words and concepts utilized in the field of psychology and their meanings in English together with mistakes done in translation are coming in the beginning of such troublesome situations. Frequently discussed concepts such as normal, criteria of normal and also concepts of gifted, talented and multiple intelligence within the framework of normal are especially the most important problems. As for the concepts of special education or normal or abnormal, the
\end{abstract}


same conceptional confusion has been observed. It can easily be understood from the observations and perusals of the articles written on these subjects that one of the real reasons of misunderstanding or misexplanation of questions such as "what is talent, what is intelligence, what is normal, what is the criteria of normal, how many kinds of abnormality is there" is the lack of knowledge about the meanings and limitations of such concepts. We would like to state that the main target of writing this article regarding specification of normal, criteria and kinds of normal is the need of clarifying the said confusion within the framework of the concept of normal.

Keywords: Normal; Anormal; Paranormal; Intellegence; Gift; Special education; Word and concept confusion.

\section{Extended Summary}

It is supposed to be a point that everyone accepts the importance of having a rich vocabulary of terms and glossary of concepts for being successful, unique (original) and in advance (actionary) in every field and from every aspect, especially in scientificity. On the other hand; differences, limitations and transitivities between terms and concepts should become so transparent that scientific success or successes can be reached. In order to make philosophy, especially to make philosophy of science, it is required and even obligatory to have a rich glossary of concepts and terms. Furthermore, it cannot be seen possible to maintain a right communication between a person who understands different meanings from the same word and another person who expresses different meanings with the same word.

In the extremely short history of psychology which is moving in the direction of being an autonomous science, difficulties in facing the needs of term and concepts brought by the efforts of becoming not only a theoretical science but also a science with its practicality as well as 
difficulties of liberating its terms form the influence of philosophy which psychology remained under its domination.

The science of psychology mostly expresses itself in English and its publications are in English especially as of today. Countries where educational and scientific language is not in English are obliged to make translations from English. Difficulties and mistakes of translation in developing countries, too, make almost impossible to solve the matters related to the terms and concepts in this field (see. Baltaş, 2008). We can express the necessary and obligatory way to be followed as minimum on behalf of tackling this problem, namely, of overcoming the mistakes arising from translation, and being able to understand psychology correctly, as follows: With the condition of not making neologism, in order to translate a term in the field of science correctly, it is required to know closely the terms and concepts of the said language where the translation to be done together with its culture, etymology etc. as well as the same aspects of other language which the word is to be translated into.

Words are like the clothes of ideas. The cloth-like words used for expressing an idea or a scientific approach are not able to reflect the same echo in everyone's consciousness. When it happens especially in psychology that is a science on the way of becoming a positive one like other sciences such as physics, chemistry and mathematics, this said point expresses more and more importance. As thought within this context, one of the most important problematic words is the concept of normal. The word of normal which is the topic of this article is one of 
the such concepts that are understood extremely difficultly.

To be able to understand the concept of normal, we can firstly and primarily divide the notions (concepts) in psychology and in psychopathology as well as the values carried by this concept into two parts as quantitative and qualitative.

Qualitative notions are firstly divide into two parts as negative and positive values. Negative values are examined in four groups as biological deficiency, integration, loss of autonomy and adaptation that is also divided into two parts as disadaptation and inadaptation. Positive values are divided into three parts as alarm reaction, phase of resistance and phase of weariness.

Quantitative notions express themselves in psychology with a measurement and are divided into two categories as statistical and gradualist. Statistical notion classifies the state of being healthy as normal and it categorizes the state of unhealthy as abnormal. If so, what is the normal?

In classifying phenomena, especially psychical phenomena, it is not enough and sufficient to call psychological phenomena as "normal" and pathological phenomena as "abnormal", that is "not normal".

When an evaluation is needed to be done under in the light of psychological meanings of the concept of normal, the concept can be understood in three categories as statistical, ideal and functional normality. 
It is understood from all the above mentioned descriptions that a necessity of using the notion of paranormal besides the words of normal and abnormal. At the same time, kinds of normal is not sufficient as the measurement of healthiness.

The science of psychology will hopefully reach a diversity of concepts which will place the importance of using the measurement of normal and the word of paranormal on a stronger ground in the coming period of time. Although it has got an extremely short history for a science, psychology succeeded diversify its field of study from behaviorism to cognition and up to human psychology and it will also place this matter on a stronger ground.

\section{Giriş}

Her açıdan ve her alanda ve bilhassa bilimsellikte başarılı, özgün (orijinal) ve önde (aksiyoner) olabilmek için zengin bir kelime ve kavram hazinesine sahip olmanın önemi herkes tarafından kabul edilen bir husustur, denilebilir. Öte yandan kelime ve kavramlar arasındaki farklar, sınırlar ve geçişlilikler de bir o kadar berrak olmalıdır ki bilimsel başarı veya başarılar olabilsin. Meselâ Amerika Kızılderililerin bir zamanlar duman işaretleri ile gönderdikleri mesajların tam içeriğini bilemesek de bu işaretlerle felsefî bir tartışma veya bilimsel bir çalıştay yapılamadığını rahatlıkla tahmin edebiliriz. Duman halkalarının varoluşun niteliği ile veya bir kimsenin psikolojik rahatsızlığının tanı ve terapisi ile ilgili fikirleri yansitabilecek karmaşıklıkta olmadığ vakıadır. Ancak bu karmaşıklığa sahip olsaydı bile, bir Cherokee filozofu daha ikinci aksiyomunu iletmeye veya bir Cherokee psikoloğu 
daha ikinci terapisini gerçekleştirmeye geçmeden, önce elindeki bütün odunlarla battaniyeleri tüketmiş olurdu (Postman, 1994). Bu misâlden de anlaşılacağı ve yukarda da ifâde edildiği üzere felsefe ve bilhassa bilim felsefesi yapabilmek için zengin bir kelime ve kavram hazinesine sahip olmak gereklidir, hatta bu zarûridir. Bütün bunların yanı sıra aynı kelimelerden ayrı manâlar anlayanlarla, ayrı anlamları aynı kelimelerle ifâde edenlerin doğru bir iletişim kurabilmeleri mümkün görünmemektedir (Morin, 1999).

Günümüz psikolojisinin özerk bir bilim olma yolundaki gayretleri bilim tarihi açısından görece yeterli bir zaman geçirmiş değildir. Hatta diğer bilim dalları ile kıyaslandığında tarihî açıdan başlangıcından bu yana çok kısa sayılabilecek bir süre geçmiştir de denilebilir (Maher ve Spitzer, 1998). On sekizinci yüz yıla kadar felsefe, din, edebiyat ve tıp ile karışmış bir durumda olan psikoloji bilimi ancak yukarda ifâde edilen asırdan beri özerk bir bilim olma gayretleri içerisine girmiştir.

Özerk bir bilim olma yolunda ilerleyen psikolojinin çok kısa tarihi geçmişinde bir taraftan sadece teorik değil, aynı zamanda pratiği olan bir bilim olma gayretlerinin getirdiği yeni kelime ve kavram ihtiyaçlarını karşılamadaki zorluklarının yanı sıra, iki bin yıl hâkimiyetinde kaldığ zorluğu söz konusu bilim alanını bir hayli müşkül durumda bırakmaktadır. Meselâ irâde (voluntary) kelimesini bir örnek olarak verebiliriz. Felsefede ve eğitim felsefesinde irâde ve irâdecilik (voluntary, volutourisme) kullanılırken hatta bizde irâdecilik ve Batı felsefesinde 
voluntarisme diye bilinirken, günümüz psikolojisinde yönetici işlevlerle (executive founction) beraber irâde ve irâdecilikten sosyal psikolojide çok nadir olarak daha yeni söz edilmeye başlanmış olması konu hakkında bir fikir verebilir.

Makalenin asıl konusu olan normalle de ilintili olması münasebeti ile yani sınıflardaki öğrenciler nitelenirken üstün zekâlıların da diğerlerinin de genelde anormal olarak ifâde edilişinden ötürü üstün zekâ ve üstün yetenek kavramlarındaki karışıklık da burada zikredilebilir. Günümüz Türkiye'sinde çoklu zekâ kavramı anlatılırken İngilizcedeki "gift" kelimesi Türkçeye zekâ diye çevrildiği takdirde Wechsler'in teorisindeki "wise", “wisdom" ve "intellect" kelimeleri Türkçeye ne diye tercüme edilecektir. Gift kelimesi zekâ olarak alındığında "mind" kelimesi nasıl anlamlandırılacaktır. Gift kelimesi üstün zekâ anlamında alındığında çok hızlı koşan bir maratoncu veya ağırlık kaldıran bir haltercinin İngilizcedeki ability, can, talent, skill kelimelerinden biri ile anlatılması yanlış mı olacak? Bir başka ifâde ile maratonda, halterde, vs. spor dallarında birinci olanlar ne diye adlandır1lacak? Üstün zekâlı mı, yoksa üstün yetenekli mi? Bu İngilizcede hangi kelime ile ifâde edilecek? Öte yandan Yaratıcı vergisi, doğuştan getirilen, tabîi bir yetenek anlamına gelen; İncil'de, seçilmiş özel insanlara verilmiş ilahî hediye anlamı da taşıyan, Batı'da karizma kavramının da dayandırıldığ 1 gift kelimesinin sinonimlerine bir göz atıldığında “donation, present, talent, donate, give, allowance, alms, award, benefaction, benefit, bequest, bestowal, bonus, boon, bounty, charity, courtesy" kelimelerini görürüz. Bunların hangisi acaba zekâ anlamını vermekte- 
dir. Yani "intellect" veya eş anlamlıları olan "acumen, brains, cerebration, comprehension, egghead, genius, intellectual, intellectuality, intelligence, intuition, judgment, mentality, mind, psyche, pundit, reason, savvy" (Neufeldt ve Guralnik, 1988) kelimelerinin hangisi gift anlamını vermektedir? Çok güzel öten bir horoz veya kuş ne tür zekâya sahip olmuş olacak? Sesi çok güzel olan ve bütün ömrünce sadece icracı olabilen ve fakat bütün sesleri çok güzel taklit edebilen ve bunun yanı sıra, her sesi hançeresinden rahatça çıkarabilen bir insan İngilizcedeki "gift" kelimesi ile anlatınca zekî olduğuna mı hükmedilecek? Yani, "gift" kelime anlamı olarak Tanrı tarafından verilmiş bir hediye anlamındaki kelimenin etimolojisinden türetilmiş ise; "gift"i veren Tanrı o takdirde zekâ, yetenek, zihin ve netice olarak insanın sahip olduğu bütün şeyleri bize vermemiş mi olacak veya kim vermiş denecek? $\mathrm{Bu}$ alana yönelik etnosemantik bir araştırma, bilişsel yetileri göstermek için farklı kültürlerde kullanılan kelimeleri çözümleyerek işe başlayabilir. Farklı dillerde hemen hemen aynı kavram için çeşitli kelimelerin kullanılıyor olması gayet dikkat çekicidir. Meselâ, Amerikan toplumunda olağanüstü zeki kabul edilebilecek bir çocuğun genellikle "parlak" olduğu söylenir, oysa aynı niteliklere sahip bir Fransız çocuğu "akıllı (bilge, ağırbaşlı)" olarak tanımlanır, Meksika dilindeki muadil terim "çabuk kavrayan” anlamındadır. Başka bir örnek olarak ise Zimbabwe"nin Shona dilinde bizim zekâ olarak tanımladığımız kavrama en yakın olan kelime "ngware"dir, ancak bu terim özellikle sosyal mes'elelerde ihtiyat, sağduyu ve yetkinlik kavramlarını da akla getirir (Price-Williams, 1975) (akt; Bock, 2001). 
Psikoloji bilimi büyük çoğunlukla, bilhassa günümüzde İngilizce lisânının hâkim olduğu ülkelerde ve İngilizce olarak kendisini ifâde etmekte ve yayın yapmaktadır. Eğitim ve bilim dili/lisânı İngilizce olmayan ülkeler İngilizceden tercüme yapmak mecburiyetinde kalmaktadırlar. Gelişmekte olan ülkelerdeki psikoloji bilimi ile ilgilenmek isteyenlerin aşmak zorunda oldukları yukarda ifâde edilen psikoloji biliminin sıkıntılarının yanı sıra tercümedeki zorluklar ve hatalar da bu alandaki kelime ve kavramlara ait meseleleri nerede ise içinden çıkılmaz bir duruma getirmektedir. Bu problemi aşabilmek, yani çeviriden kaynaklanan hataları aşıp psikolojiyi doğru anlayabilmek adına, asgarî takip edilmesi gerekli ve zorunlu olan yol şöyle özetle ifâde edilebilir (bkz. Baltaş, 2008). Neologisme düşmemek şartı ile bilimsel alandaki bir kelimeyi doğru tercüme edebilmek için;

a. Çevirisi yapılan lisânın (İngilizcenin) bilhassa çevrilen kelimeye ait kültür, çevrilen kelimenin etimolojisi, söz konusu kelimenin ilk kullanılmaya başlandığında kullanılma neden ve niçini, günümüze kadar kullanılırken anlam kazanımı mı, anlam kaybı mı, anlam kayması mı olmuş çok iyi bilinmelidir.

b. Hangi lisâna çeviri yapılıyor ise çeviri yapılan lisândaki söz konusu çevrilen kelimeyi karşılayacağı düşünülen o kelimenin kültürü, etimolojisi, ilk kullanılmaya başladığı andan bugüne kadar geçen süre içerisinde anlam kazanımı mı, anlam kayması mı, anlam kaybı mı olduğunun çok iyi bilmesi gerekmektedir. 
Yukarıdaki zorlukları aştıktan sonra bir de her bilim alanının kelimelere yüklediği anlamı ve kelimelerin tabiri câizse kapsam alanlarını da bilmek ayrı bir maharet istemektedir. Bir başka ifâde ile kelimeler fikrin libasıdır. Bir fikri, bilimsel bir anlayışı ifâde etmek için kullanılan elbise kelimeler, her zihinde aynı yankıyı uyandırmayabiliyor. Mesela vak'a kelimesinin bir tıpçı ile bir hukukçuda aynı tedâileri (çağrışımları) yapmayacağı aşikârdır. Bu, bilhassa fizik, kimya ve matematik gibi pozitif bir bilim yolunda olan psikoloji bilimi olunca ayrı bir ehemmiyet ifâde etmektedir. İşte bu makaleye konu olan normal kavramı da bir hayli zor anlaşılabilen kavramlardan (mefhumlardan) biri olarak görülmektedir. Meselâ herhangi bir sınıfta derse giren bir öğretmen, öğretmenler odasına geldiğinde derse girdiği s1nıftan bahsederken "derse girdiğim bu sınıfta iki tane özel öğrenci veya iki tane anormal (abnormal) öğrenci var” demiş olsa bu durumda bu iki anormal öğrenciden neyi kastettiğini nasıl anlayacağız? Normalaltı için -subnormal- kelimesini kullanmış olsun (Budak, 2009). Normalüstü zekâya -ki "gifted" kelimesini Türkçeye üstün zekâlı diye yanlış tercüme edilmektedir ve üstün yetenekli diye çevrilmelidir- sahip olan öğrenci için hangi kelimeyi kullanmalıdır? Normalin altı ve normalin üstü için aynı kelimeyi kullanmış olsa yani anormal iki öğrenci var demiş olsa bu durumda bu cümleden ne anlaşılacak? İşte bu kargaşayı önlemek ve farkı ortaya çıkarmak için paranormal kelimesini kullanmak mümkün müdür? Kullanılsa yanlış mı olur? Bu ve benzeri sorular çoğaltılabilir. Ancak normalaltı ile normalüstünü ayırt edecek anormal ve paranormal kavramlarını kullanmak, zekâ geriliği ile üstün zekâlıyı ayırt ederken bunun kolayca ifâde edilebilmesine ve yanlış anlaşılmayı 
asgariye indirmeye imkân sağlayacaktır. Paranormal kelimesini daha iyi anlaşılabilmesi için psikolojideki kavramların sınıflandırmasına ve normal kavramının menşeine bakmak fevkalâde elzem bir durum arz etmektedir.

Normal kavramını anlayabilmek için önce psikolojideki ve psikopatolojideki mefhumlar (notion), bu kavramın taşıdıkları değerler öncelikli olarak nicel (kantitatif, kemmî) ve nitel (kalitatif, keyfî) olmak üzere iki bölüme ayrılabilir. Doğrudan bu konuyla ilgili olmadığı için nitel kavramlardan sadece kategorize edilmiş hâli ile bahsetmek, normal kavramını içine aldığı için ise nicel kavramları daha teferruatlı anlatmak uygun olacaktır (Doksat, 1975).

Nitel kavramlar evvela negatif ve pozitif değerler diye ikiye ayrılır. Negatif değerler ise; biyolojik noksanlık, entegrasyon, otonominin kaybolması, adaptasyon -ki dezadaptasyon ve inadaptasyon diye ikiye ayrılır- şeklinde dört grupta incelenir. Pozitif değerler ise; alarm reaksiyonu, direnç safhası ve bitkinlik safhası olmak üzere üç bölüme ayr1lir.

Kantitatif kavramlar psikolojide görünüşü itibari ile kendini bir ölçü ile ifâde ederek istatistik ve gradüalist olmak üzere iki kategoriye ayrılır. İstatistik kavram sağlıklı olmayı normal, sağlıklı olmamayı da anormal olarak kategorize eder. O hâlde normal nedir?

Normal kelimesinin orijinini bilmeden yukarıdaki soruyu doğru cevaplandırmak bir hayli zor olacaktır. 
Norm: "Norme", Latince gönye, cetvel anlamına gelen bir kelime. Bu anlamı ile kânuna hizmet eden, kâideye elverişli prensip anlaminadır. Buna göre norm tip, model ve kâide demektir. Normal ise kâideye uygun, kâideye uyan, mûtad, olağan demektir. Matematikteki anlamı ise amudî, dikey demek olur (Neufeldt ve Guralnik, 1988).

Fenomenleri, özellikle psişik fenomenleri sınıflandırırken, psikolojik olanlara "normal", patolojik olanlara "anormal" yani normal olmayan demek kâfi gelmiyor, yetmiyor. Normal olmayan; fakat patolojik anlamına a-normal de kabul edilmeyen bir başka psişik fenomenler kategorisi var ki bunlara da para-normal deniliyor.

"Para" ön takısı "karşı" anlamından başka "yanında, komşusu" anlamlarını da ifâde eder. Para-normal denilince normalin komşusu, normalin yanında oluşan, fakat alışılmış (mûtad) olmayan, sık rastlan1lmayan kastedilmektedir.

Normal, istatistik kânunu tarafından "vasatî=ortalama" olarak tanımlanmaktadır. Bu hâle göre anormal manâsına patolojik, vasatîden yani, ortalamadan basit bir inhiraf (sapma) olarak anlaşılır.

İstatistikteki normali değerlendirmek için meşhur çan (gauss) eğrisi kullanılır. Astronomi, optik, manyetizm v.s. üzerine çalışmaları ile meşhur olan Carl Friedrich Gauss'un (1777-1855) çan şeklindeki ünlü eğrisi bir kânuna tâbi fenomenleri göstermek için kullanılmaktadır. Buna göre normalin psikolojideki anlamları şöyle ifâde edilir: 
1. Bir ferdin (bireyin) karakteristikleri, normali gösteren eğrinin dişında değilse ve mensup olduğu toplumun değişim çeşitliliklerinin sınırları (hudutları) içinde bulunuyorsa, o ferde normal denir.

2. Bir bölüştürme (taksimât), bir dağıtma (tevzi, distribution) eğrisi eğer Gauss Eğrisi'ne uygunsa o eğri normali gösterir.

3. Ortalama bir tip veya karakter de normal olarak nitelendirilir.

4. Bazen ideal bir tipe de normal adı verilir.

Normalin sıhhatlilik ve anormalin patolojik ölçüsü olup olamayacağı, olursa ne dereceye kadar itibar edilebileceği kısa misâllerle anlatılabilir. Yukardaki açıklamanın ışı̆̆ı altında üç türlü normallikten söz edilebilir. Bunlar özetle şu şekildedir;

a. İstatistik Normalite: İstatistik normallik, toplumsal (içtimâî, sosyal) norma uygun oluş ve sık rastlanış ile aynı anlamda kullanılmaktadır. Bir şeyin bu manâda normal oluşu, ona pek sık rastlandığını, onun pek sık gözlemlendiğini, olağan, mûtad olduğunu söylemek demektir. Fakat sırf istatistik bakımdan normal ölçüsü kolaylıkla reddedilebilir. Öyle hâller vardır ki bu ölçü geçerli (mu’teber) sayılmaz. Meselâ ender rastlanan dâhîleri normlara uymadığ kabul etmeye imkân var mıdır?

Kızamık hastalığının da sık rastlandığı için normal mi kabul edilmesi gerekir? Dördüz veya beşiz doğurma nâdirdir diye anormal ve 
sonuç olarak hastalıkvâri mi kabul edilecektir? Eğer istatistik eğrisi (bell curve) Gauss Eğrisi gibi çan şeklinde değil de düz bir çizgi şeklinde ise objektif olarak normallik ile anormallik arasında hiçbir kesin sinır tespit edilemez. O zaman artık istatistik olmayan kriterlerden ve kavramlardan (mefhumlardan) medet ummak gerekecektir. Yani niceleyici kavramlar kâfî gelmediği için niteleyici mefhumlardan faydalanılacaktır. Özetle istatistik normalitenin tek başına yeterli bir kavram ve ölçü olmadığı bir vakıadır.

b. İdeal Normalite: Genellikle kökeni toplumsal olan bir anlayıştır. İdeal norm, toplumdan topluma değişecektir. Zira her toplumun ideal anlayışı farklıdır. Bir toplumun ideal saydığı tipe uygun olanlar, ideal normaldir. Diğer bir cemiyetin ideali başka olacağından, onun ideal normali de başka olacaktır. İdeal norma uygunluk bakımından ele alınınca, normal ile anormal arasındaki fark da -istatistik normalliğin kantitatif ölçüsünün zıddına- kalitatif olacaktır. Diğer taraftan, ideal norma nazaran süjelerin dağıtım ve bölüştürülmesini bir grafikle gösterince Gauss Eğrisindeki gibi çan şeklinde bir curve değil, ters $\mathrm{j}$ harfi şeklinde bir eğri çıkar. Bu konuda Gordon Willard Allport'un meşhur misâline bakılabilir.

İstatistik normalite ile ideal normalite birbirinden müstakil değillerdir. Bir davranışın normdan sapışı, uzaklaşışı hususundaki subjektif intibâ o davranışın enderliği nisbetindedir, yani nâdir oluşu ile orantılıdır. Bu durum bilhassa suçların bizde uyandırdığı intibâ ve o suçlar hakkında bu intibâlara göre hüküm verişimizle gâyet âşikâr bir 
şekilde anlaşılabilir. Bir suçun ağırlık derecesinin sübjektif ölçüsü ve bu vehâmetin yaptırımı (müeyyidesi) onların nâdir olup olmayışları ile doğrudan doğruya orantılıdır. Diğer taraftan bir davranışın sıklığına ait bilgi o davranışın artık nâdir olmadığına kanaat getirmek yani, istatistik normalite, ideal normalite telâkkisinin değişmesine yol açar.

Konuyu daha anlaşılır kılmak için birkaç benzetme misâli verilebilir. Bir sınıfta öğrenciler genellikle tembel olsunlar. Derslerden on üzerinden beşten yukarı not alamasınlar. Eğer bu tembel öğrencilerin arasından biri ortaya çıkar da on almayı başarırsa bu öğrenci o sınıf ölçüsünde istatistik normaliteye göre anormal, ideal normaliteye göre ise normaldir. Zamanla öğrencilerin birbirleri ile kıyasıya bir yarışa girip hepsinin on almaya başladıklarını farz edilsin. O takdirde ideal normalite ölçüsü değişir. Artık on almak kâfi gelmez olur. Not olarak on almanın ötesinde öğrencilerden başka yetenekler de istenir ve o yetenekler de işin içine girerek ideal öğrenci skalası on almakla seçilmez olur.

c. Fonksiyonel Normalite: $\mathrm{Bu}$ bakımdan normal ölçüsü şöyle ifâde edilebilir. Bir ferdin (bireyin) varmak istediği hedeflere, gâyelere ve karakteristiklerine uygun düşen bir hâlde olması normaldir. Gelişmiş, kıvamını bulmuş şahsiyet (kişisellik), psikolojik açıdan sağlam olma gibi mefhumlarda, fonksiyonel normallik kavramları kullanılmaktadır. Yukarıda verilen sınıf misâlinde tembel ve sürekli âzamî beş puan alan öğrencilerin amaçları sınıfı geçmektir. Ve fakat, şayet zekâ kapasitelerine ve kabiliyetlerine uygun olarak randimanlı ve muntazam bir 
şekilde çalışırlarsa beş puan ile değil de yedi alarak sınıfı geçebilirler. Bütün gayretlerine rağmen on değil de meselâ ancak yedi alarak geçebilseler, bu onların fonksiyonel normalitesini gösterir.

Bütün bu anlatılanlardan anlaşılan o ki normal ve anormal kelimelerinin yanı sıra paranormal kavramını kullanmanın zarureti ile birlikte sıhhatliliğin ölçüsü olarak normalin çeşitleri de yeterli gelmemektedir.

Psikoloji bilimi ilerleyen zaman dilimi içerisinde normalin ölçüsü ve paranormal kelimesini kullanmanın önemini daha sağlam zemine oturtacak bir kavram çeşitliliğine ve ölçüsüne kavuşacaktır. Zîra bir bilim için çok kısa bir süre olarak kabul edilecek geçmişine rağmen davranışçılıktan (behaviourism), bilişselciliğe (cognitive) ve oradan da insanî (human psychology) psikolojiye kadar çalışma sahasını çeşitlendiren psikoloji bilimi bu konuyu da daha sağlam bir zemine oturtacaktır.

\section{Kaynakça}

Baltaş, Z. (2008). Sağlık psikolojisi. İstanbul: Remzi Kitabevi.

Bock, P. K. (2001). Insan davranışının kültürel temelleri. Ankara: İmge Kitabevi.

Budak, S. (2009). Psikoloji sözlüğü. Ankara: Bilim ve Sanat Yayınları.

Doksat, R. (1975). Psikopatolojiye giriş. Adana: Çukurova Üniversitesi Yayınları. 
Maher, B. A. ve Spitzer M. (1998). Felsefe ve psikopatoloji. İstanbul: Gendaş Kültür Yayınları.

Morin, E. (1999). Seven complex lessons in education for the future. Paris: UNESCO Publishing.

Neufeldt, V. ve Guralnik, D. B. (1988). Webster's new world dictionary (4. bask1). New York: Simon\&Schuster Inc.

Postman, N. (1994). Televizyon öldüren eğlence. (O. Akınhay, Çev.). İstanbul: Ayrıntı Yayınları. 